US Army Corps of Engineers ${ }_{\circledast}$

Engineer Research and

Development Center

Civil Direct Program

A Comparative Analysis of LiDAR and Structure from Motion Photogrammetry Utilizing a Small Unmanned Aerial System (sUAS) Approach for Structural Mapping and Inspection

Michael A. Schwind, Ralph A. Scheid,

August 2018

and Jonathan L. Boone

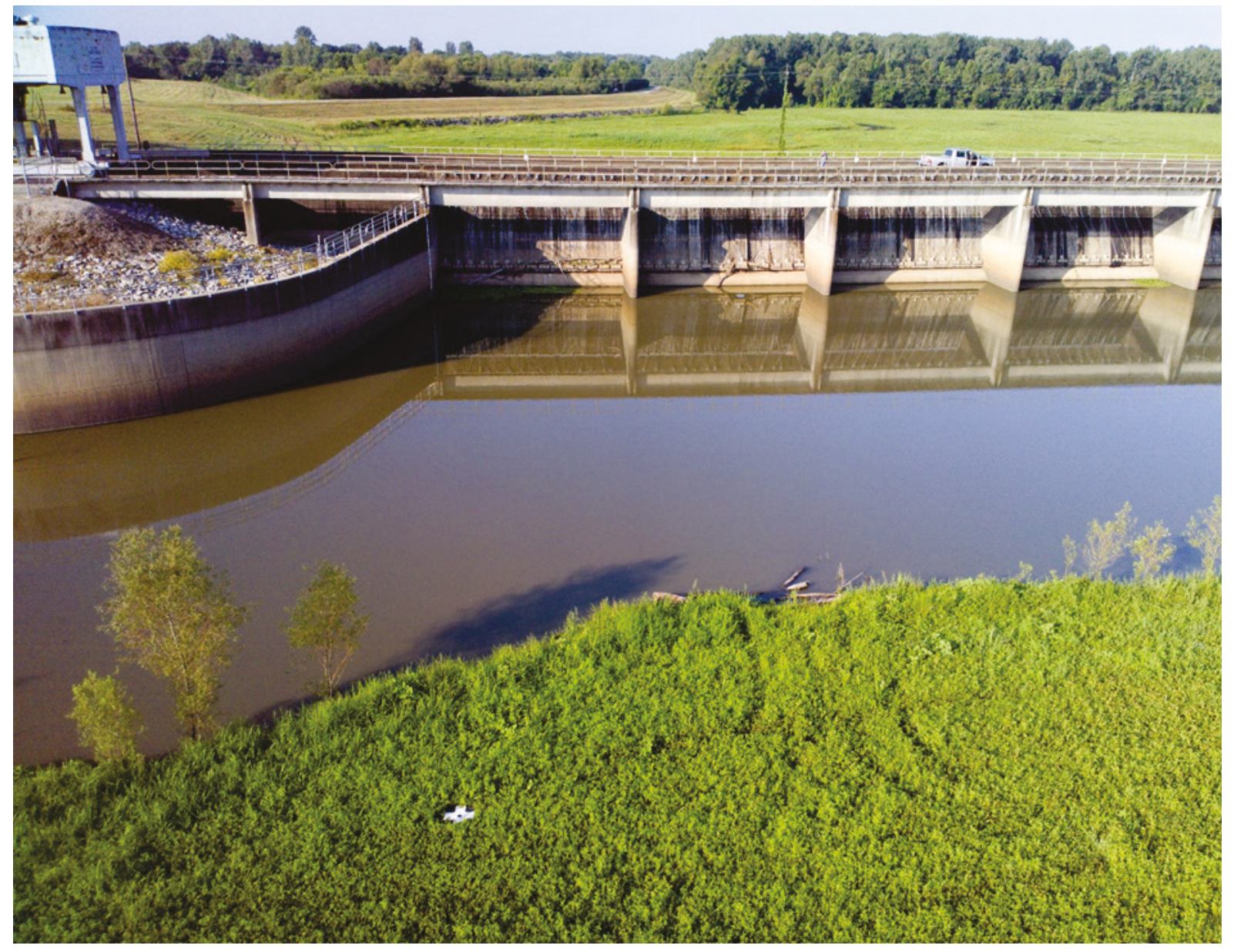


The U.S. Army Engineer Research and Development Center (ERDC) solves the nation's toughest engineering and environmental challenges. ERDC develops innovative solutions in civil and military engineering, geospatial sciences, water resources, and environmental sciences for the Army, the Department of Defense, civilian agencies, and our nation's public good. Find out more at www.erdc.usace.army.mil.

To search for other technical reports published by ERDC, visit the ERDC online library at http://acwc.sdp.sirsi.net/client/default. 


\title{
A Comparative Analysis of LiDAR and Structure from Motion Photogrammetry Utilizing a Small Unmanned Aerial System (sUAS) Approach for Structural Mapping and Inspection
}

\author{
Jonathan L. Boone \\ Information Technology Lab \\ U.S. Army Engineer Research and Development Center \\ 3909 Halls Ferry Road \\ Vicksburg, MS 39180-6199 \\ Michael A. Schwind and Ralph A. Scheid \\ U.S. Army Corps of Engineers \\ New Orleans District \\ 7400 Leake Avenue \\ New Orleans, LA 70118
}

Final Report

Approved for public release; distribution is unlimited.

\footnotetext{
Prepared for Headquarters, U.S. Army Corps of Engineers

Washington, DC 20314-1000

Under Civil Direct Program Work Unit FC65H3
} 


\section{Abstract}

The U.S. Army Corps of Engineers (USACE) field operating activities invest significant amounts of project time and funding on survey data collection by conventional methods. This data collection supports a variety of Civil Works projects spanning wide-ranging geographies and site conditions to include hard to access terrain. Innovations in small unmanned aerial systems (sUAS) (e.g., drones), and data processing techniques purport to produce survey grade data more efficiently and with greater coverage than conventional survey collection in hard to access terrain conditions.

USACE involvement in construction of our Nation's aging infrastructure will require extensive surveying. These efforts will support design and site assessments, cultural resources, and environmental determinations typically required by the National Environmental Policy Act, Endangered Species Act, Clean Water Act, National Historic Preservation Act, Migratory Bird Treaty Act, Clean Air Act, and the Archaeological Resources Protection Act.

Efforts using sUAS provide an efficient and effective technology to support these initiatives. However, sUAS technology also offers many diverse platforms and collection sensors that provide varying types of results. An evaluation of sensor types and sUAS platforms is provided.

DISCLAIMER: The contents of this report are not to be used for advertising, publication, or promotional purposes. Citation of trade names does not constitute an official endorsement or approval of the use of such commercial products. All product names and trademarks cited are the property of their respective owners. The findings of this report are not to be construed as an official Department of the Army position unless so designated by other authorized documents. 


\section{Contents}

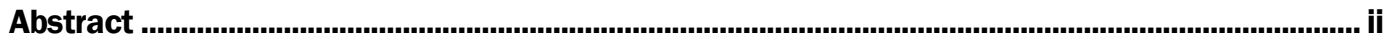

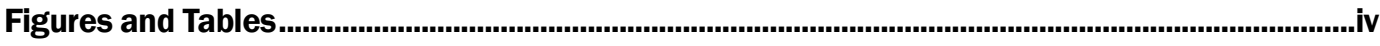

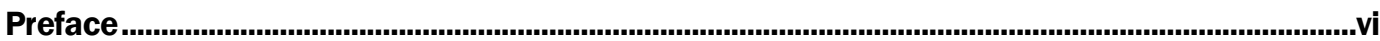

Acronyms and Abbreviations ...........................................................................................................vii

1 Introduction: the Importance of the Investigation ......................................................................

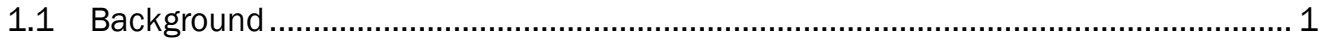

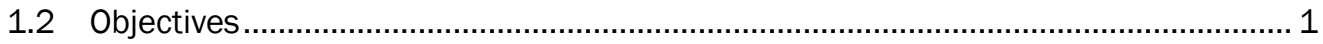

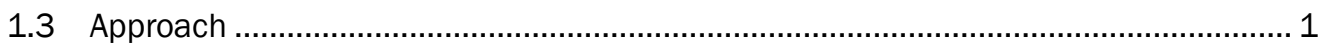

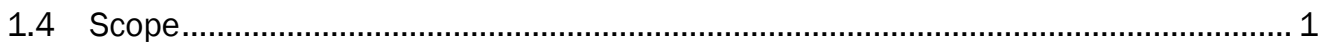

2 Methodology ....................................................................................................................... 3

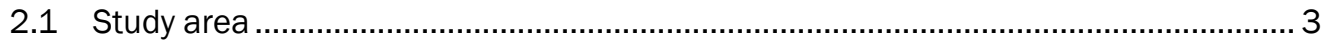

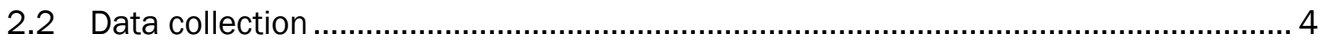

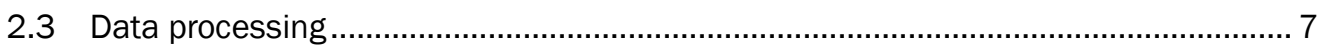

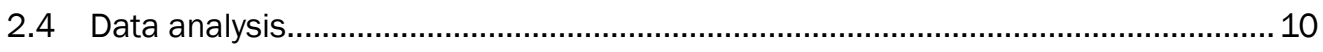

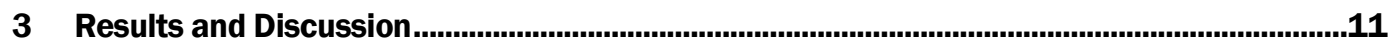

3.1 Visual inspection ................................................................................... 11

3.2 Point cloud characteristics and statistics........................................................ 14

3.3 Accuracy analysis............................................................................................ 16

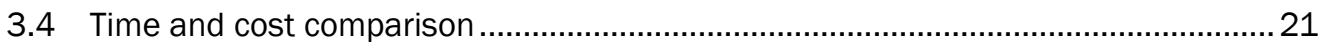

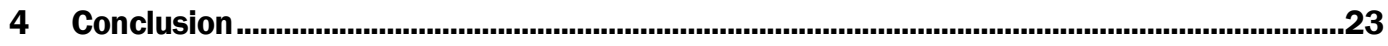

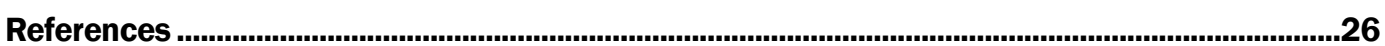

Report Documentation Page 


\section{Figures and Tables}

\section{Figures}

Figure 1. The USACE-owned Old River Control Complex near Simmesport, Louisiana.

Figure 2. The senseFly eBee RTK and the senseFly Albris were used to collect sequences of overlapping imagery to use as an input for the SfM photogrammetric processing.......................... 4

Figure 3. The Riegl RiCOPTER used to collect the LiDAR data............................................................. 4

Figure 4. The location of each ground control target. .................................................................... 6

Figure 5. The cluttered SfM point cloud (left) vs. the cleaned SfM point cloud (right) colored by elevation.

Figure 6. The cluttered SfM point cloud (left) vs. the cleaned SfM point cloud (right) colored by RGB value.

Figure 7. The inflow side of the Overbank structure. The SfM point cloud (left), displays clutter points along the top guard rail as well as gaps along the side where deep shadows fell on the structure. The LiDAR point cloud (right), displays sharper edges and cleaner surfaces, but with less density (fewer points) along the side. Each point cloud is colored by elevation.

Figure 8. The outflow side of the Overbank structure. The SfM point cloud (left), shows jagged edges along the front faces of some piers, but displays some points along the pier underneath the deck. The LiDAR point cloud (right), shows sharp edges, but shows few points underneath the deck. Each point cloud is colored by elevation......

Figure 9. The SfM point cloud (left), successfully reconstructed the deck of the structure, showing a clean deck with little to no spurious points above or below it. The LiDAR point cloud (right), also shows a clean deck. Point clouds colored by RGB value.

Figure 10. The top image shows an oblique perspective of the SfM point cloud while the bottom is the corresponding image of the same segment of the structure. This highlights some of the major causes of clutter that was seen in the SfM point cloud.

Figure 11. The histogram showing the approximate point to point distances. Distances are measured in feet.

Figure 12. Result of the Cloud-to-Cloud Distance tool. The colors represent the nearest neighbor distance from the LiDAR point cloud to the SfM point cloud. The figure displays a nadir view.

Figure 13. Result of the Cloud-to-Cloud Distance tool. The colors represent the nearest neighbor distance from the LiDAR point cloud to the SfM cloud. This figure displays a profile view.

Figure 14. An oblique image of the Overbank structure taken by the albris sUAS. The ground control target (circled in yellow) is displayed at the bottom of the image.

Figure 15. A time and cost comparison between the two survey methods.

\section{Tables}

Table 1. Point cloud characteristics compared between the SFM and LiDAR point clouds.

Table 2. Comparison of the minimum, maximum, mean, and standard deviation of the $X$ coordinate between the SfM and LiDAR point clouds. 
Table 3. Comparison of the minimum, maximum, mean, and standard deviation of the $Y$ coordinate between the SFM and LiDAR point clouds.

Table 4. Comparison of the minimum, maximum, mean, and standard deviation of the Zcoordinate between the SfM and LiDAR point clouds.

Table 5. The deviation between each ground control target and its corresponding DEM pixel value. The deviation between the ground control targets and each pixel value was used to determine an RMSE value for each point cloud derived DEM. This process provides a greater understanding of how well each point cloud fit to the ground control

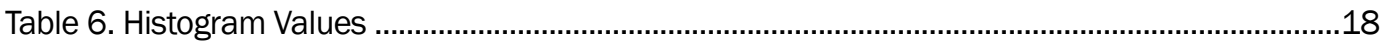




\section{Preface}

This study was conducted for the Computer-Aided Design/Building Information Modeling (CAD/BIM) Technology Center under the Civil Direct program number $\mathrm{FC}_{5} \mathrm{H}_{3}$.

The research was performed by the U.S. Army Corps of Engineers (USACE) New Orleans District and the CAD/BIM Technology Center of the Software Engineering and Informatics Division (SEID), U.S. Army Engineer Research and Development Center-Information Technology Laboratory (ERDC-ITL). At the time of publication, Mr. Edward L. Huell was the Chief of the CAD/BIM Technology Center, Mr. Ken C. Pathak was the Chief of the SEID, Ms. Patti S. Duett was the Deputy Director of ITL, and Dr. David A. Horner was the Director of ITL.

COL Ivan P. Beckman was the Commander of ERDC and Dr. David W. Pittman was the Director of ERDC. 


\section{Acronyms and Abbreviations}

BIM Building Information Modeling

CAD Computer Aided Design

CEMVN USACE New Orleans District

DoD Department of Defense

DEM Digital Elevation Model

ECs Engineering Circulars

ECBs Engineering Construction Bulletins

EL Environmental Laboratory

EMs Engineering Manuals

ERDC Engineer Research Development Center

GCP Ground Control Point

GNSS Global Navigation Satellite System

GPS Global Positioning System

HD High-Definition

ITL Information Technology Laboratory

LiDAR Light Detection and Ranging

MP Megapixel

MPH Miles Per Hour

RGB Red, Green, Blue

RMSE Root Mean Squared Error

RTK Real Time Kinematic

SBET Smoothed Best Estimate of the Trajectory

SEID Software Engineering and Informatics Division

SfM Structure from Motion

SIFT Scale Invariant Feature Transform

UAS Unmanned Aerial Systems

sUAS small Unmanned Aerial Systems 


\section{USACE U.S. Army Corps of Engineers}

3D Three-Dimensional 


\section{Introduction: the Importance of the Investigation}

\subsection{Background}

Unmanned aerial systems (UAS) technology has been rapidly deployed in industry and within the U.S. Army Corps of Engineers (USACE) at a rate outpacing development of Engineering Construction Bulletins (ECBs), Engineering Circulars (ECs), and Engineering Manuals (EMs).

\subsection{Objectives}

An investigation is necessary to evaluate small unmanned aerial systems (sUAS) data products against the time and cost differences between the two methods. While Light Detection and Ranging (LiDAR) is a widely accepted and trusted form of surveying, structure from motion (SfM) photogrammetry is considerably less expensive and often times more efficient.

\subsection{Approach}

To investigate the possible use of sUAS to map and inspect structures (i.e., bridges and walls), two sensors will be used to conduct a survey of a spillway structure. A LiDAR scanner affixed to a Riegl RiCOPTER sUAS and a consumer grade digital camera carried by two senseFly sUASs (eBee, Albris) were used. These platforms were selected because they are common within USACE. The New Orleans District (CEMVN) currently owns the senseFly platforms and has contractual access to the RiCOPTER.

\subsection{Scope}

These two methods of surveying, while resulting in a similar dataset, are inherently different from each other. LiDAR is an active sensor, producing its own energy and emitting billions of laser pulses that reflect off objects and return to the sensor allowing it to determine the distance and location of objects. A digital camera used for SfM Photogrammetry is a passive sensor and relies on the sun's reflected electromagnetic energy to impose photons upon the focal plane of the camera to capture an image of the scene. Because a passive sensor relies on the reflected energy of sunlight, it 
cannot capture images of objects that fall within deep shadows. If objects cannot be seen in the areas of deep shadowing in the imagery, the resulting SfM point cloud will exhibit holes or gaps where the shadows coincide. This could become a challenge when imaging a bridge or wall that requires investigation.

The resulting LiDAR data was compared to the SfM photogrammetry derived data, this determined the quality of each dataset and the sUASs capability for structural mapping and inspection purposes. Characteristics and statistics of the LiDAR and SfM derived point clouds were compared and characterized, this gained a greater understanding of the differences between the two data collection methods. The point cloud to point cloud distance was computed to see how well the two datasets agreed spatially, and characteristics such as point density and spacing were compared. Statistics such as the standard deviation, minimum, maximum, and average of the $\mathrm{X}, \mathrm{Y}$, and $\mathrm{Z}$ coordinates were also recorded for each point cloud.

This research can provide engineers and scientists information directly applicable to all ongoing civil works projects in planning, engineering, and design. 


\section{Methodology}

\subsection{Study area}

The USACE-owned Old River Control Complex near Simmesport, Louisiana (Figure 1) offered varying structures and geography that were suitable for the project. The structure chosen as the subject for this project was the Overbank Structure, a 3,356 foot spillway featuring 73 bays, each 44 feet wide, with a weir crest elevation of 52 feet above sea level. The length and number of bays that this structure offers would make it a time consuming and difficult structure to survey using traditional methods, and therefore, was chosen as a prime subject for this sUAS project.

Figure 1. The USACE-owned Old River Control Complex near Simmesport, Louisiana.

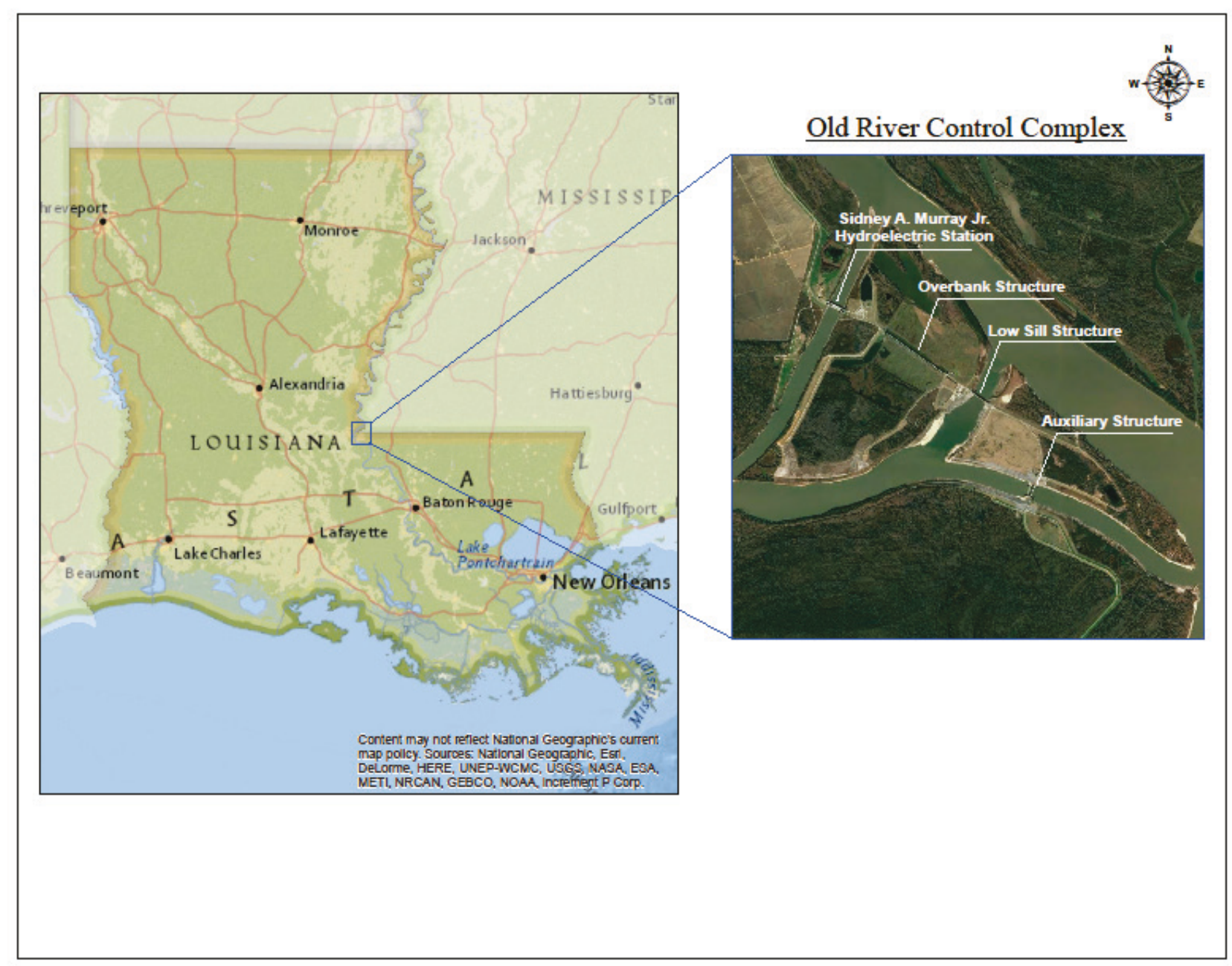




\subsection{Data collection}

Three different types of sUAS were employed to collect the LiDAR and SfM data. The Riegl RiCOPTER was used for LiDAR collection. The senseFly eBee RTK and albris were used to collect sequences of overlapping imagery for the SfM photogrammetric processing input (Figures 2 and 3).

Figure 2. The senseFly eBee RTK and the senseFly Albris were used to collect sequences of overlapping imagery to use as an input for the SfM photogrammetric processing. senseFly eBee RTK senseFly albris

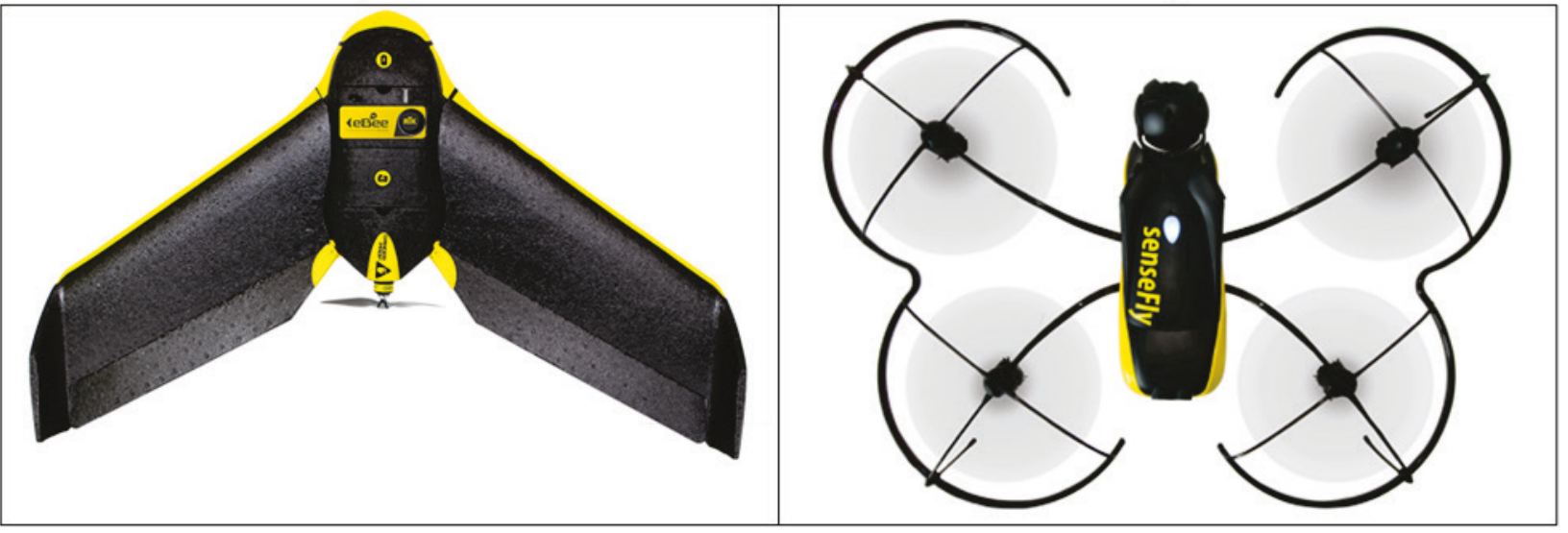

Figure 3. The Riegl RiCOPTER used to collect the LiDAR data.

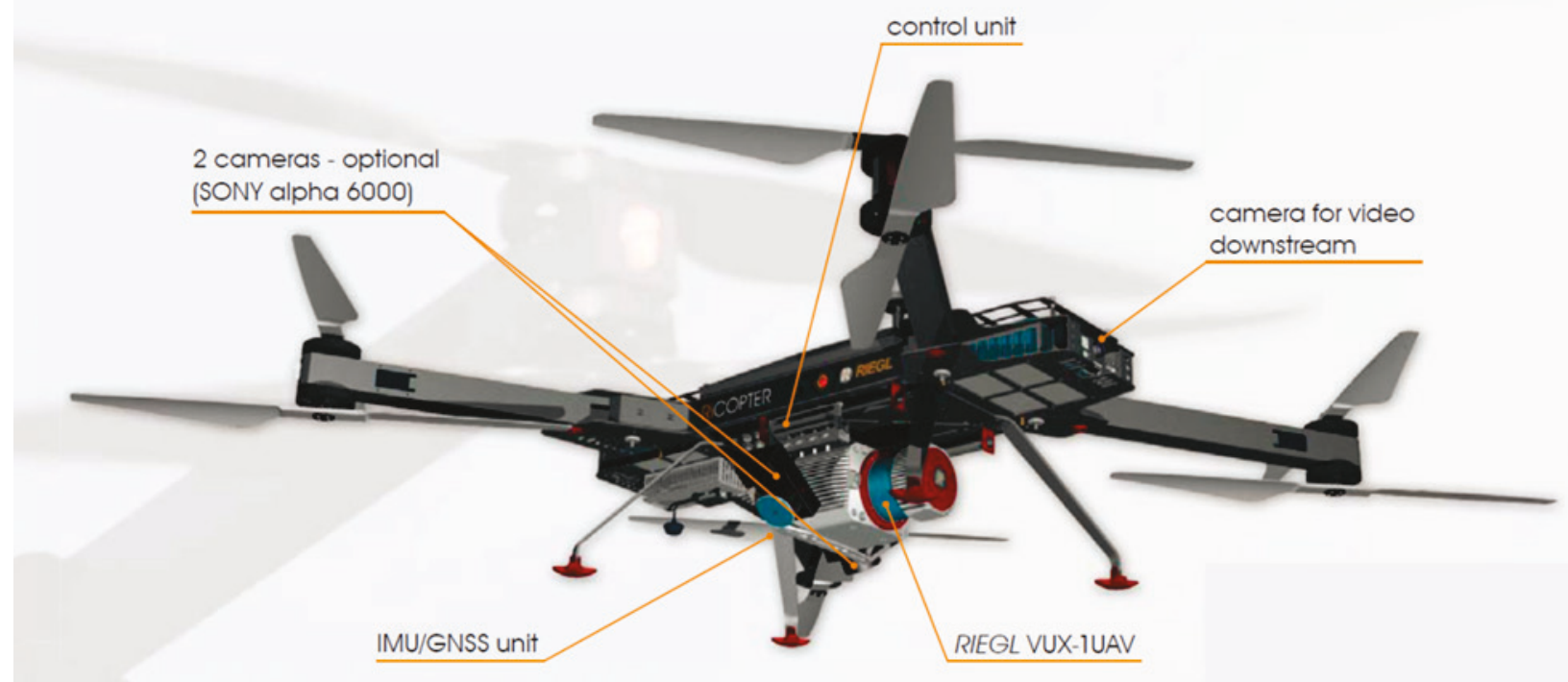

The Riegl RiCOPTER is a large octocopter (X8 configuration) platform weighing approximately 55 pounds with a maximum flight endurance of 30 minutes (Figure 3). It is outfitted with the Riegl VUX-SYS that is comprised of an Applanix IMU (a survey grade GPS/GLONASS receiver), 
and two Sony A600 24.3 mega pixel cameras mounted at oblique angles (used for point cloud colorization). It also includes the Riegl VUX-1UAV lightweight airborne laser scanner that provides a 230 degree field of view, an effective measurement rate up to 350,00o measurements per second, and ten millimeter ( $\mathrm{mm}$ ) accuracy.

The eBee RTK has a wingspan of 37.8 inches and weighs 1.61 pounds including the camera and the battery, and has a flight time of up to 40 minutes. It is user friendly and fully autonomous with the use of the eMotion3 flight planning software.

The albris is a V-shaped fixed wing drone that weighs 3.9 pounds including the battery, payload and shrouding, and has a flight time of up to 22 minutes (Figure 2). It boasts a triple view head that allows the user to switch between High-Definition (HD) and thermal video imagery while capturing high resolution still images on demand. The triple-view head also features a 180 degree vertical range of motion, 6x digital zoom, and active gimbal stabilization.

Prior to flying the sUAS, a network of eight ground control targets were placed, four on either side of the structure (U.S. Army Corps of Engineers, Vicksburg District 2016). Each ground control target was surveyed with a Trimble R10 real time kinematic (RTK) global positioning system (GPS) at 180 epoch observations per target. This resulted in highly accurate locations for the ground control target network. The targets later served as the means for georectifying the resultant point clouds to real world vertical and horizontal coordinates. All sUAS utilized the same ground control network in an attempt to decrease the spatial disagreements between the final data products. The ground control network can be seen in Figure 4. 
Figure 4. The location of each ground control target.

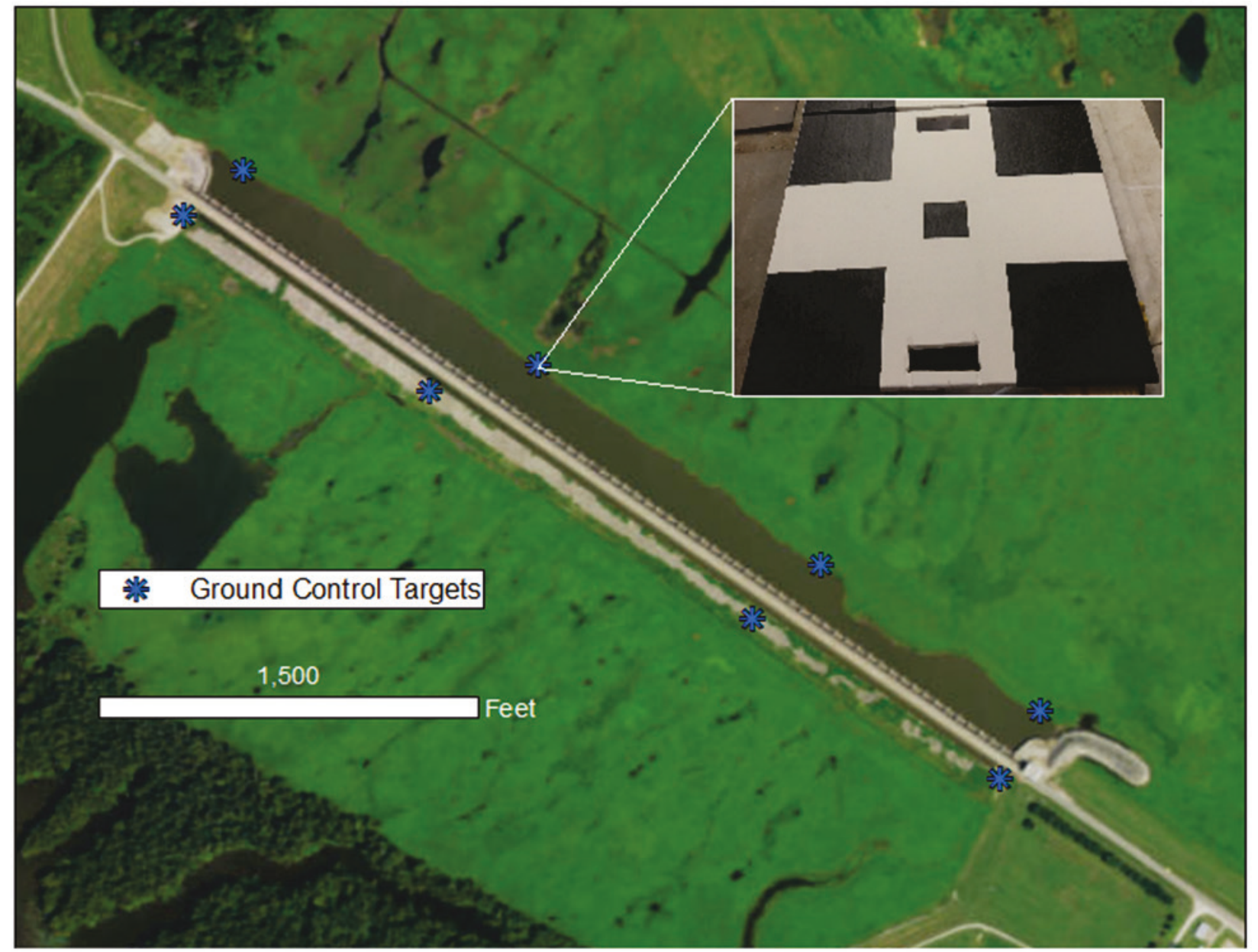

The Riegl RiCOPTER flew a preprogrammed flight that traveled approximately 100 feet off of each side and parallel to the structure. Its operating altitude was set to 131 feet above ground level and traveled at a speed of 18 miles per hour (MPH). The LiDAR data collection flight was completed in nine minutes.

When collecting imagery with a sUAS for SfM processing, it is crucial to remember the importance of overlapping photos so that features are present in multiple images. Feature matching algorithms rely on this principle, and therefore, the higher the overlap the images have (in theory), the more features should be matched across the scene. Consistent, straight flight lines and perfectly nadir images are often unobtainable when flying a sUAS, this is due to wind, GPS error, or manual flight error. Fortunately, this typically does not hinder the ability for features to be matched due to the nature of the SfM processing. Some researchers would even suggest that these inconsistencies actually increase the overall quality of the final products. 
The fully autonomous senseFly eBee RTK was used to capture images of the top of the structure. The flight was planned using eMotion 3 flight planning software to fly at 352 feet above ground level, this allowed for a one inch ground sample distance (one pixel in the image is equal to one inch on the ground). The side image overlap was set to $75 \%$, and the forward image overlap was set to $85 \%$. The sensor used for this flight was the G9X RGB camera that is offered by senseFly. The flight took fifteen minutes and 216 images were collected.

The albris fixed wing drone was used to collect imagery of each side of the structure. The head that houses the sensors on this platform is capable of rotating 180 degrees, making it an ideal sUAS for capturing high resolution oblique imagery. The albris carries a 38 megapixel (MP) red, green, blue (RGB) camera with a mechanical shutter, this was used to capture high resolution imagery of each side of the Overbank structure. This platform also features a cruise control capability, allowing it to maintain a constant heading and speed without user input. This function was used to maintain a speed of three knots and a constant offset distance of 150 feet from the structure along with an auto trigger function that automatically triggered the camera every four seconds. The speed at which the albris was flown, along with the high camera trigger interval, provided sequences of high overlapping imagery of each side of the structure. Each ground control target was successfully captured in the bottom of the oblique images, adding to the precision of the geo-rectification of the final SfM point cloud. A total of 312 images were taken of the sides of the Overbank structure in a 30-minute time period.

\subsection{Data processing}

The LiDAR data processing was performed by Chustz Surveying, LLC and was completed at their facility. The LiDAR data was initially processed using Riegl RiPROCESS, this allows the user to take the raw LiDAR data and time match it against the smoothed best estimate of the trajectory (SBET) data to produce a trajectory based, geo-referenced point cloud. The second step was to align the flight line data. This is based on the premises that LiDAR data is of higher precision then that of the inertial navigation system and Global Navigation Satellite System (GNSS). Technicians used a combination of manual and automated techniques to find planner surfaces, tie points, and planes in the data set. Once these objects were located, they were used to calculate a least squares, best fit adjustment to the trajectory. Once this was complete, the ground control points were 
imported into the project to verify the accuracy of the data. It was found that the LiDAR data was slightly higher than that of the ground control points. To adjust for this, a small translation adjustment was applied to the trajectory/LiDAR data.

SfM uses images acquired from multiple camera perspectives in order to resolve three-dimensional geometry of objects and surfaces. It is a computer vision technique based heavily on the principles of photogrammetry, wherein, a significant number of photographs taken from different, overlapping perspectives are combined to recreate an environment (Wolf and Dewitt 2000). SfM however, is significantly different from traditional photogrammetry. The main difference between the two is the use of new image matching algorithms, such as the scale invariant feature transform (SIFT) algorithm that allows for unstructured image acquisition (Lowe, 1999). A crucial property of these new image matching approaches is the ability to recognize conjugate features (physical features present in many images) in multiple images despite dramatic differences in the image scale and viewpoint. While traditional photogrammetry utilizes kernel-based image correlation approaches calculated with image convolution operators, algorithms such as SIFT utilize multiscale image brightness and color gradients to identify points in images that can be identified as conjugate (Wolf and Dewitt 2000). The use of multiple scales in the SIFT key means images with varying resolution are not an issue.

There are many SfM processing software packages available and the one utilized by the CEMVN is Pix4D. This software takes sequences of overlapping images taken by a sUAS and utilizes an image matching algorithm to determine the three-dimensional (3D) location of recognizable features. All of the images taken of the Overbank structure by the senseFly eBee RTK and albris were processed with Pix4D, along with the ground control targets, in order to obtain a $3 \mathrm{D}$, georectified point cloud of the structure.

Because SfM point clouds are inherently cluttered, filters had to be applied in order to clean them up. This was done through the CloudCompare point cloud processing software. This tool was utilized to discriminate points based on their RGB values, and then separate them accordingly. The RGB value of the concrete structure was easily isolated from the surrounding vegetation and water RGB values, and therefore, could be separated from most of the clutter. However, this method did not clean the point cloud 
completely. The point cloud was manually cleaned with a segment tool offered by CloudCompare where spurious points can be manually clipped out (Girardeau-Montaut 2011). Finally, lasnoise, a tool offered by LasTools, was used to classify the noise in the point cloud and remove it. An example of the cluttered point cloud and the cleaned point cloud can be seen in Figures 5 and 6.

Figure 5. The cluttered SfM point cloud (left) vs. the cleaned SfM point cloud (right) colored by elevation.
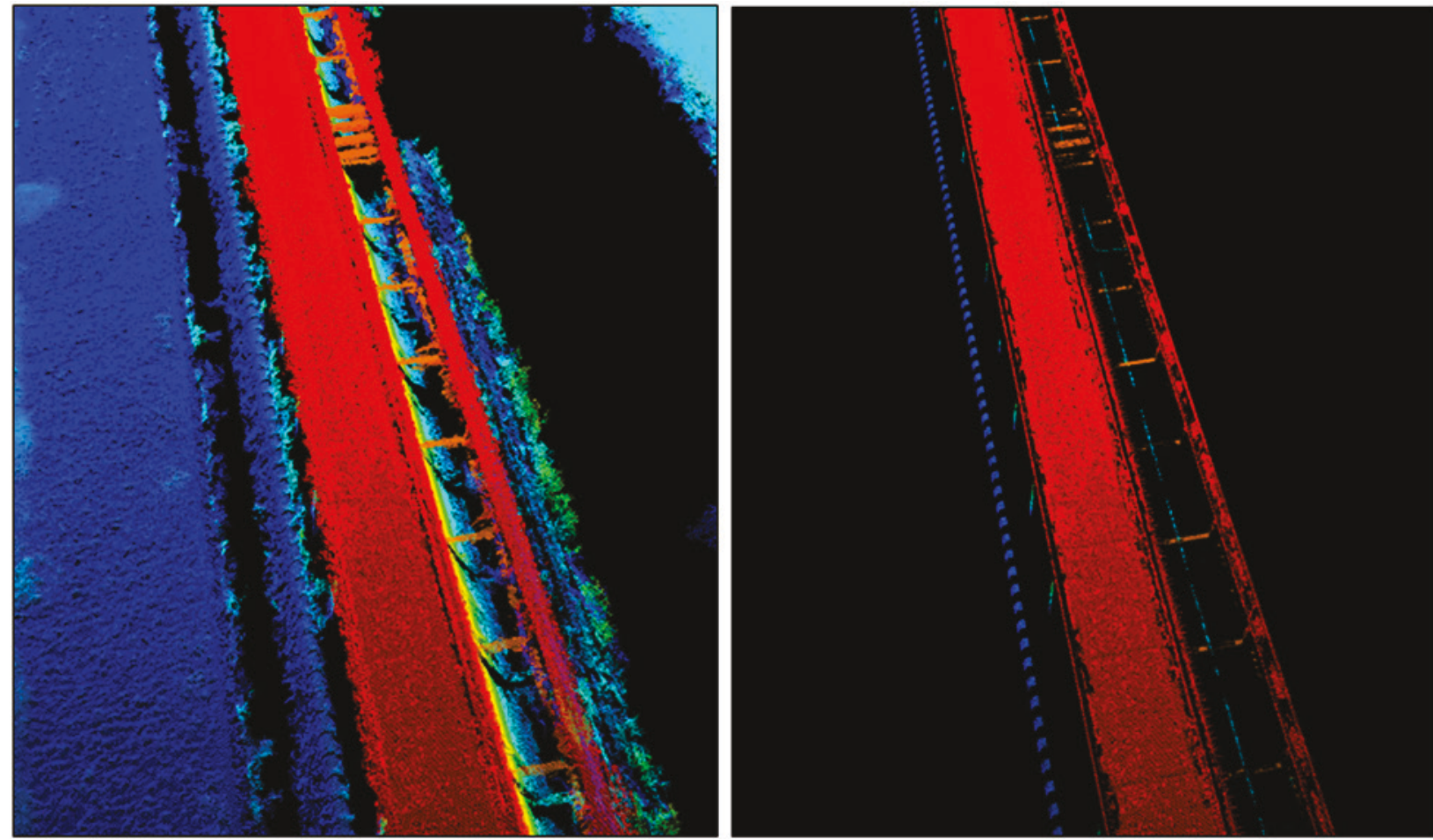

Figure 6. The cluttered SfM point cloud (left) vs. the cleaned SfM point cloud (right) colored by RGB value.
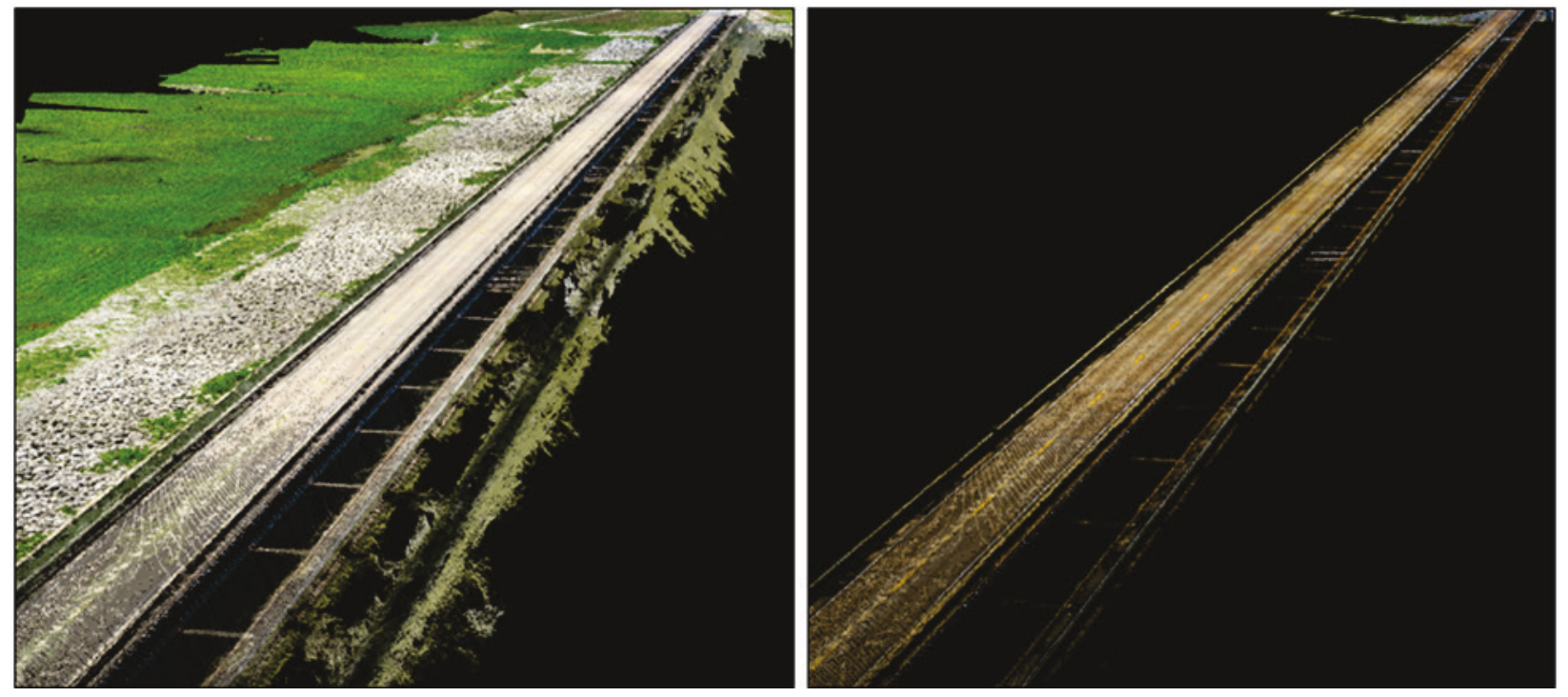


\subsection{Data analysis}

In order to understand the differences between the LiDAR point cloud and the SfM point cloud, a number of characteristics and statistics were investigated. However, a visual analysis was the first component of the data analysis. It is important to visually inspect the data for common problems large number of spurious points, point clouds that have been incorrectly reconstructed, or those that were given the wrong coordinate reference system).

After a general visual inspection was complete, the two point clouds were checked spatially to determine how well they coincided in real space. This was done by using the Cloud-to-Cloud Distance tool offered by CloudCompare (http://cloudcompare.org/) (Girardeau-Montaut 2011). This tool computes the distance between two point clouds by taking in a reference cloud and computing the nearest neighbor distance from each point to a nearest point in the compared point cloud. The reference cloud is the point cloud that is used as to compute distances relative to its points, while the compared cloud is the one on which distances will be computed. CloudCompare computes the distances of each of its points relative to the reference cloud (Girardeau-Montaut 2011). The output of this tool is a point cloud that is colored by the computed distances.

The two data sets were then opened in Quick Terrain Reader (http://appliedimagery.com/download/), a point cloud viewing software. This software is capable of reading the information regarding the point clouds. It was used to determine the point density, point spacing, the standard deviation, minimum, maximum, and average of the horizontal and vertical coordinates. 


\section{Results and Discussion}

\subsection{Visual inspection}

An initial visual inspection of the point clouds identified differences between the two datasets. It was quickly noted that the LiDAR point cloud was overall cleaner, with less clutter and sharper edges. The clutter that was seen in the SfM point cloud was directly related to the inherent challenges within SfM technology. In this case, the most clutter was seen clustered along each side of the structure and was caused by the water that existed along the entire length of the structure on either side. SfM photogrammetry fails to reconstruct scenes where water is present, this is due to the absence of unique features for feature matching algorithms to match on. Water processed by SfM techniques often results in misplaced and noisy points surrounding the area. These noisy points caused by water often intermixed with valid three-dimensional points of the area surrounding the water, making them difficult to discriminate and remove. For this project, a large portion of the water caused spurious points were able to be classified by their RGB value and removed from the point cloud. Very calm water also caused the SfM process to reconstruct the reflection of the structure, causing a mirror image of the structure below the actual structure.

Another cause of SfM clutter were the deep shadows of the structure's interior. Because SfM relies on reflected energy, it does not reconstruct areas with shadows very well. For this model, it attempted to reconstruct the areas within each bay, but failed to do so where deep shadowing occurred. The final cause of clutter that was seen in the SfM cloud was the background features in the oblique imagery. The trees and grass that were visible in the background of the oblique images were reconstructed correctly for the most part. However, some of the background features that could be seen through the structures guard rails and substructure were reconstructed incorrectly in the point cloud, and were placed in and amongst the correctly reconstructed points of the structure. Because these points were intermixed with correct data and lacked a discriminatory RGB value, it was very difficult to properly classify and remove them. A large portion of these points were manually clipped from the point cloud.

While the sides of the structure displayed a large amount of noise in the SfM point cloud, the deck (top) was overall clean. There was some cluttering along the edges of the deck, but these were easily removed with 
the use of an RGB discrimination filter. A visual comparison of the deck between the SfM and LiDAR point clouds showed relatively little difference. The nadir images that were acquired with the eBee RTK and used to generate the top of the point cloud resulted in clean data with little noise. It was the oblique imagery taken by the albris that caused most of the clutter in the SfM derived point cloud. The technique of acquiring oblique images for side reconstruction of a SfM point cloud is useful, but often leads to extended processing time due to the amount of clutter that is generated from it.

While the SfM point cloud proved to be cluttered and required extensive filtering and clipping, the LiDAR point cloud was sharp and clean. This is because LiDAR is an active sensor that does not rely on the subject being well illuminated by the sun. LiDAR also interacts very well with hard surfaces (i.e., concrete and metal), resulting in sharp edges and clean surfaces. It was noted that the LiDAR did not capture the entirety of the piers underneath the deck with high density. This was most likely due to the angle of incidence that the laser had on the structure, preventing a large number of lasers from making it to the interior of the structure. The following Figures $(7-10)$ show examples of the visual differences be-tween the SfM and LiDAR point clouds.

Figure 7. The inflow side of the Overbank structure. The SfM point cloud (left), displays clutter points along the top guard rail as well as gaps along the side where deep shadows fell on the structure. The LiDAR point cloud (right), displays sharper edges and cleaner surfaces, but with less density (fewer points) along the side. Each point cloud is colored by elevation.

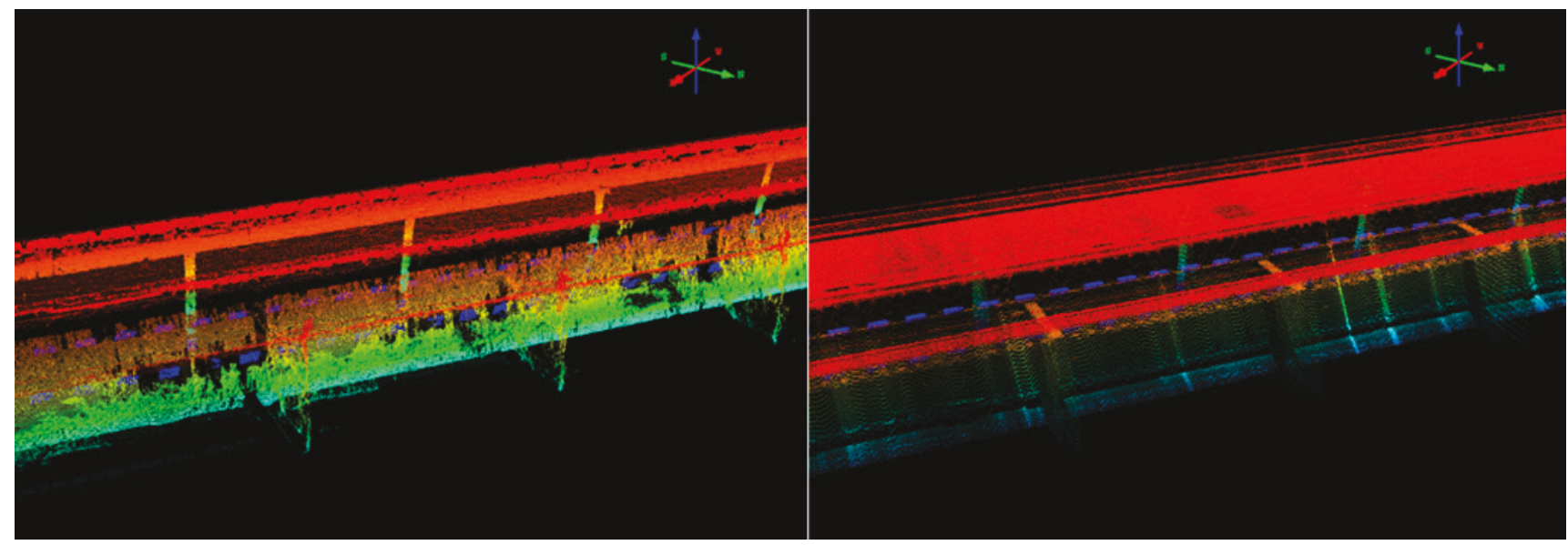


Figure 8. The outflow side of the Overbank structure. The SfM point cloud (left), shows jagged edges along the front faces of some piers, but displays some points along the pier underneath the deck. The LiDAR point cloud (right), shows sharp edges, but shows few points underneath the deck. Each point cloud is colored by elevation.

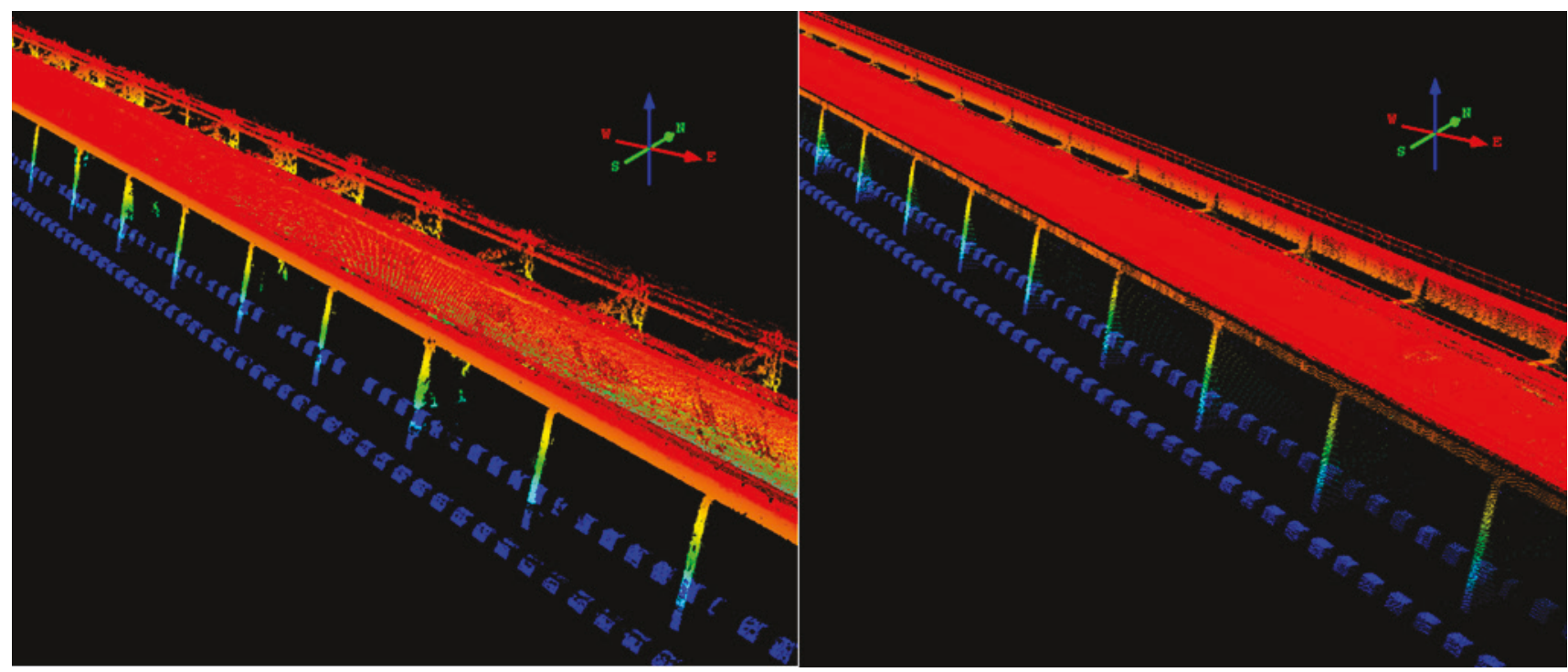

Figure 9. The SfM point cloud (left), successfully reconstructed the deck of the structure, showing a clean deck with little to no spurious points above or below it. The LiDAR point cloud (right), also shows a clean deck. Point clouds colored by RGB value.
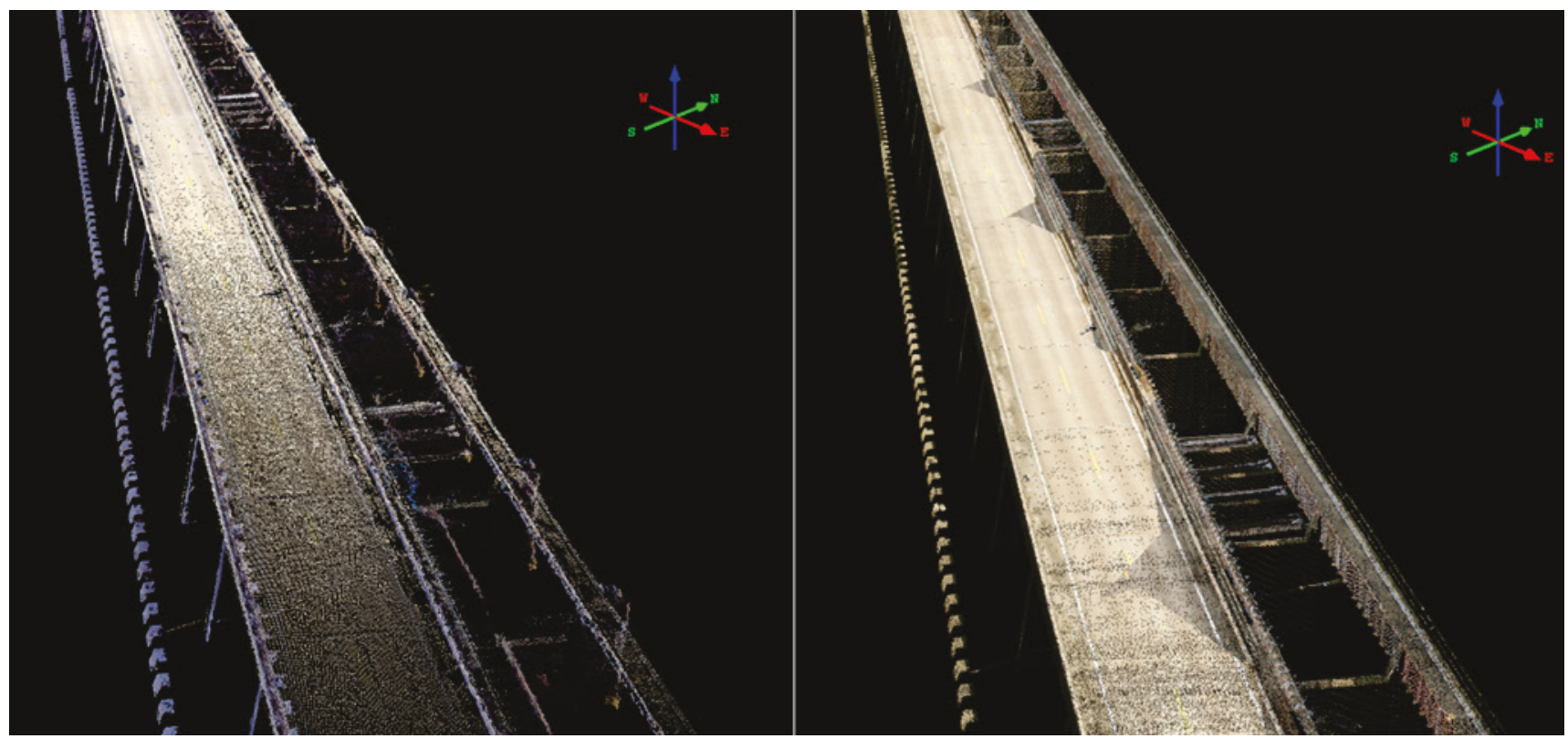
Figure 10. The top image shows an oblique perspective of the SfM point cloud while the bottom is the corresponding image of the same segment of the structure. This highlights some of the major causes of clutter that was seen in the SfM point cloud.

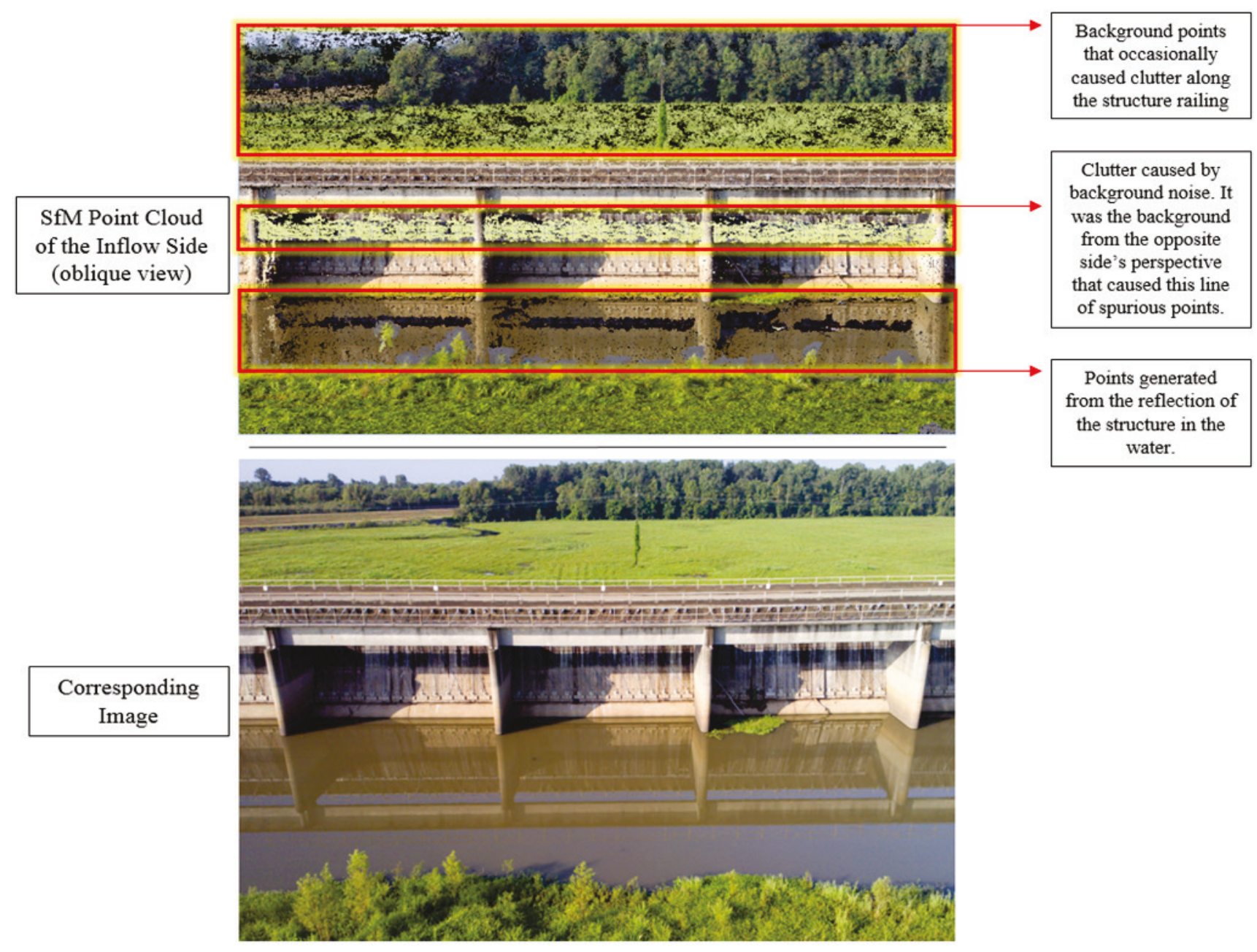

\subsection{Point cloud characteristics and statistics}

To understand how the point clouds compare beyond visual differences, characteristics and statistics were analyzed and recorded for each. This included the point cloud density, point spacing, and total number of points including the standard deviation, minimum, maximum, and average of the $\mathrm{X}, \mathrm{Y}$, and $\mathrm{Z}$ coordinates. By looking at these types of characteristics, it was able to determine which data collection method yielded the largest number and density of points, as well as the minimum and maximum extent of the data in the $\mathrm{X}, \mathrm{Y}$ and $\mathrm{Z}$ direction. LiDAR data is overall more accepted and trusted than SfM data in the workforce and scientific community. The purpose of recording this information was to determine if the SfM point cloud characteristics resemble that of the LiDAR, and whether or not the two reside within the same extent. Tables 1 through 4 display the recorded characteristics and statistics. 
Table 1. Point cloud characteristics compared between the SfM and LiDAR point clouds.

\begin{tabular}{|c|c|c|c|}
\cline { 2 - 4 } \multicolumn{1}{c|}{} & Density (points/ft ${ }^{2}$ ) & Spacing (feet) & Total No. of Points \\
\hline SfM Point Cloud & 54.204 & 0.12 & $13,060,006$ \\
\hline LiDAR Point Cloud & 41.156 & 0.15 & $9,993,272$ \\
\hline
\end{tabular}

Table 2. Comparison of the minimum, maximum, mean, and standard deviation of the X-coordinate between the SfM and LiDAR point clouds.

\begin{tabular}{|c|c|c|c|c|}
\cline { 2 - 5 } \multicolumn{1}{c|}{} & Min X (feet) & Max X (feet) & Mean X (feet) & StdDev X (feet) \\
\hline SfM Point Cloud & $3,193,660.00$ & $3,196,560.69$ & $3,195,134.76$ & 820.965 \\
\hline LiDAR Point Cloud & $3,193,659.06$ & $3,196,559.38$ & $3,195,089.24$ & 830.2142 \\
\hline
\end{tabular}

Table 3. Comparison of the minimum, maximum, mean, and standard deviation of the Y-coordinate between the SfM and LiDAR point clouds.

\begin{tabular}{|c|c|c|c|c|}
\cline { 2 - 5 } \multicolumn{1}{c|}{} & Min Y (feet) & Max Y (feet) & Mean Y (feet) & StdDev Y (feet) \\
\hline SfM Point Cloud & $938,207.41$ & $940,264.38$ & $939,200.97$ & 571.3766 \\
\hline LiDAR Point Cloud & $938,205.37$ & $940,264.37$ & $939,244.24$ & 581.6163 \\
\hline
\end{tabular}

Table 4. Comparison of the minimum, maximum, mean, and standard deviation of the Z-coordinate between the SfM and LiDAR point clouds.

\begin{tabular}{|c|c|c|c|c|}
\cline { 2 - 5 } \multicolumn{1}{c|}{} & Min Z (feet) & Max Z (feet) & Mean Z (feet) & StdDev Z (feet) \\
\hline SfM Point Cloud & 41.353 & 75.9 & 65.7457 & 8.4957 \\
\hline LiDAR Point Cloud & 45.208 & 76.79 & 69.7414 & 6.784 \\
\hline
\end{tabular}

There is a large amount of information that can be gleaned from Tables 1 through 4. The SfM point cloud has a higher density than the LiDAR point cloud at 54.204 points per square foot while the LiDAR had a density of 41.156. The spacing of the SfM data was 0.12 feet while the LiDAR was 0.15. The total number of points was 13,060,006 for the SfM point cloud and 9,993,272 for the LiDAR point cloud. The horizontal extent of the SfM point cloud was very similar to that of the LiDAR, showing that the two point clouds reside in approximately the same horizontal plane. The Zcoordinate shows how well the two point cloud extents align vertically. The minimum Z-value for the SfM point cloud was 41.353 feet while the LiDAR was 45.208 feet, a difference of 3.855 feet. This difference is most likely described by the amount of data that had to be clipped from the SfM point cloud along the bottom edge of the structure. The water caused a large amount of data to be incorrectly reconstructed, and therefore, had to be clipped out in order to keep the spurious points from affecting the quality of the entire point cloud. The maximum Z-value for the SfM point cloud was 75.9 feet while the LiDAR was 76.79, a difference of 0.89 feet. This of course does not mean that the entire LiDAR point cloud resides 0.89 feet above the SfM point cloud. It simply means that one point in the LiDAR point cloud is 0.89 feet above the highest point in the SfM cloud. The X, Y 
and $\mathrm{Z}$ statistics show that the two point clouds reside in the same approximate space relative to each other.

\subsection{Accuracy analysis}

To estimate the vertical accuracy of each point cloud, a digital elevation model (DEM) was interpolated through the LiDAR data and the SfM data in order to generate a continuous surface where each pixel contained an elevation value. Each DEM was generated at a 0.5 feet resolution (each DEM pixel represents 0.5 feet on the ground). This resolution was chosen after analyzing the greatest point spacing (LiDAR) of 0.15 feet. A DEM resolution of 0.5 feet allowed a minimum of three discrete points from each point cloud to influence the interpolated value of each DEM pixel. The difference between the ground control point (GCP) elevation and the DEM pixel elevation that it coincided with was recorded for both the LiDAR generated DEM and the SfM generated DEM. After these differences were determined, they were used to calculate the root mean squared error (RMSE) for each. The RMSE is the standard deviation of the residuals that measures how concentrated the data is around the line of best fit. The closer the value is to zero, the more concentrated the residuals are. This calculation revealed that the SfM derived DEM fit the ground control targets more precisely with an RMSE value of 0.0739 feet, while the LiDAR derived DEM resulted in an RMSE value of 0.2761 feet. Table 5 reflects these values.

The final analysis that was conducted determined how well the two derived point clouds aligned spatially. The Cloud-to-Cloud Distance tool offered by CloudCompare was used for this purpose (Girardeau-Montaut 2011). The tool takes a compared point cloud and a reference point cloud and determines the nearest neighbor distance between the two. These distances are then reflected by a colorized point cloud (hosted by the compared cloud). The colorized output point cloud gave us a greater understanding of how the two datasets deviated from each other spatially. Figures 11-13, and Table 6 display these results. 
Table 5. The deviation between each ground control target and its corresponding DEM pixel value. The deviation between the ground control targets and each pixel value was used to determine an RMSE value for each point cloud derived DEM. This process provides a greater understanding of how well each point cloud fit to the ground control target network.

\begin{tabular}{|c|c|c|c|}
\hline $\begin{array}{c}\text { Ground } \\
\text { Control } \\
\text { Pt ID }\end{array}$ & $\begin{array}{c}\text { GCP Elevation } \\
\text { (ft) }\end{array}$ & LiDAR (DEM) Elevation (ft) & SfM (DEM) Elevation (ft) \\
\hline 1 & 58.001 & 58.0383 & 57.987 \\
\hline 2 & 46.270 & 46.190 & 46.334 \\
\hline 3 & 45.818 & 45.7633 & 45.908 \\
\hline 4 & 56.180 & 56.2325 & 56.320 \\
\hline 5 & 50.375 & 51.0957 & 50.4749 \\
\hline 6 & 49.917 & 49.9877 & 49.910 \\
\hline 7 & 49.904 & 50.1423 & 49.9049 \\
\hline 8 & 50.250 & 50.3732 & 50.209 \\
\hline & & LiDAR (DEM) Deviation (ft) & SfM (DEM) Deviation (ft) \\
\hline & & 0.0373 & 0.014 \\
\hline & & 0.08 & 0.064 \\
\hline & & 0.0547 & 0.09 \\
\hline & & 0.0525 & 0.14 \\
\hline & & 0.7207 & 0.0999 \\
\hline & & 0.0707 & 0.007 \\
\hline & & 0.2383 & 0.0009 \\
\hline & & 0.1232 & 0.041 \\
\hline & & LiDAR RMSE $=0.2761$ feet & SfM RMSE $=0.0739$ feet \\
\hline
\end{tabular}


Figure 11. The histogram showing the approximate point to point distances. Distances are measured in feet.

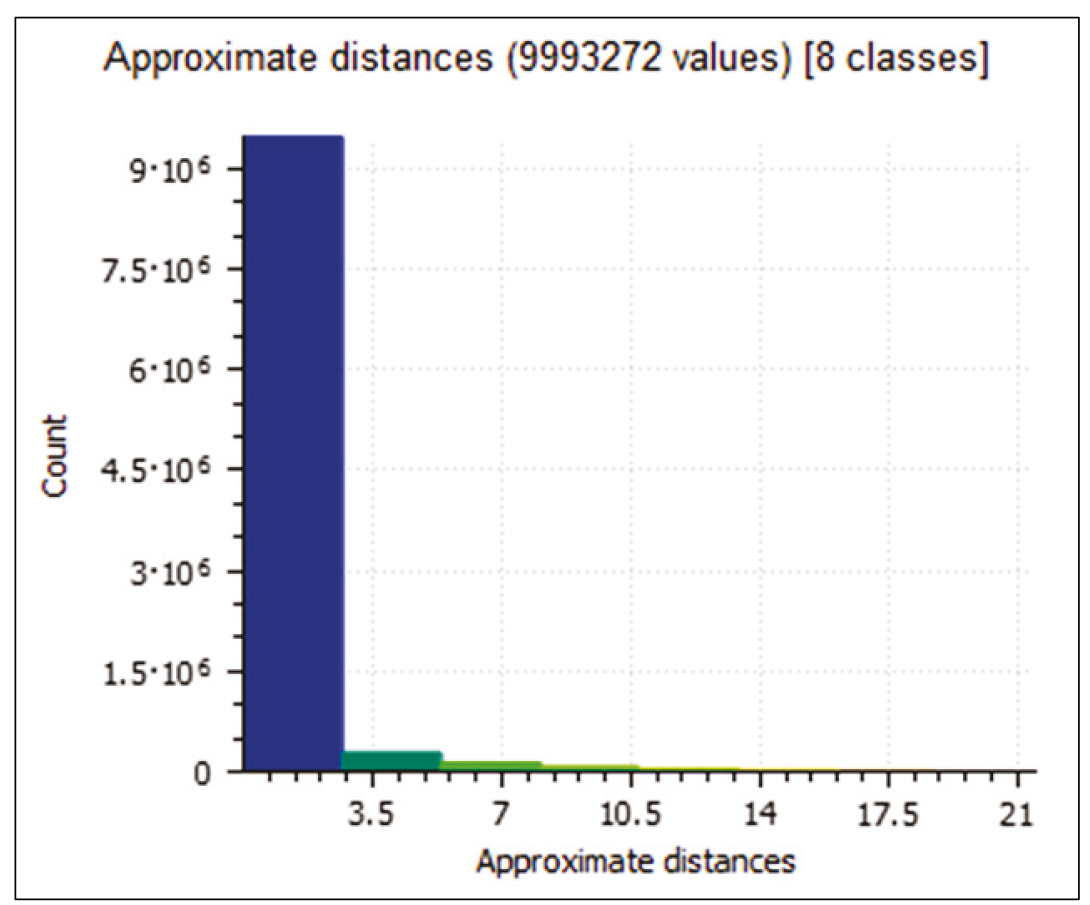

Table 6. Histogram values.

\begin{tabular}{|c|c|c|c|}
\hline Class & Value & Class start & Class end \\
\hline 1 & 9475819 & 0.000711881 & 2.687575726 \\
\hline 2 & 277245 & 2.687575726 & 5.37443957 \\
\hline 3 & 125895 & 5.37443957 & 8.061303414 \\
\hline 4 & 60824 & 8.061303414 & 10.74816726 \\
\hline 5 & 35206 & 10.74816726 & 13.4350311 \\
\hline 6 & 12242 & 13.4350311 & 16.12189495 \\
\hline 7 & 4980 & 16.12189495 & 18.80875879 \\
\hline 8 & 1061 & 18.80875879 & 21.49562263 \\
\hline
\end{tabular}


Figure 12. Result of the Cloud-to-Cloud Distance tool. The colors represent the nearest neighbor distance from the LiDAR point cloud to the SfM point cloud. The figure displays a nadir view.

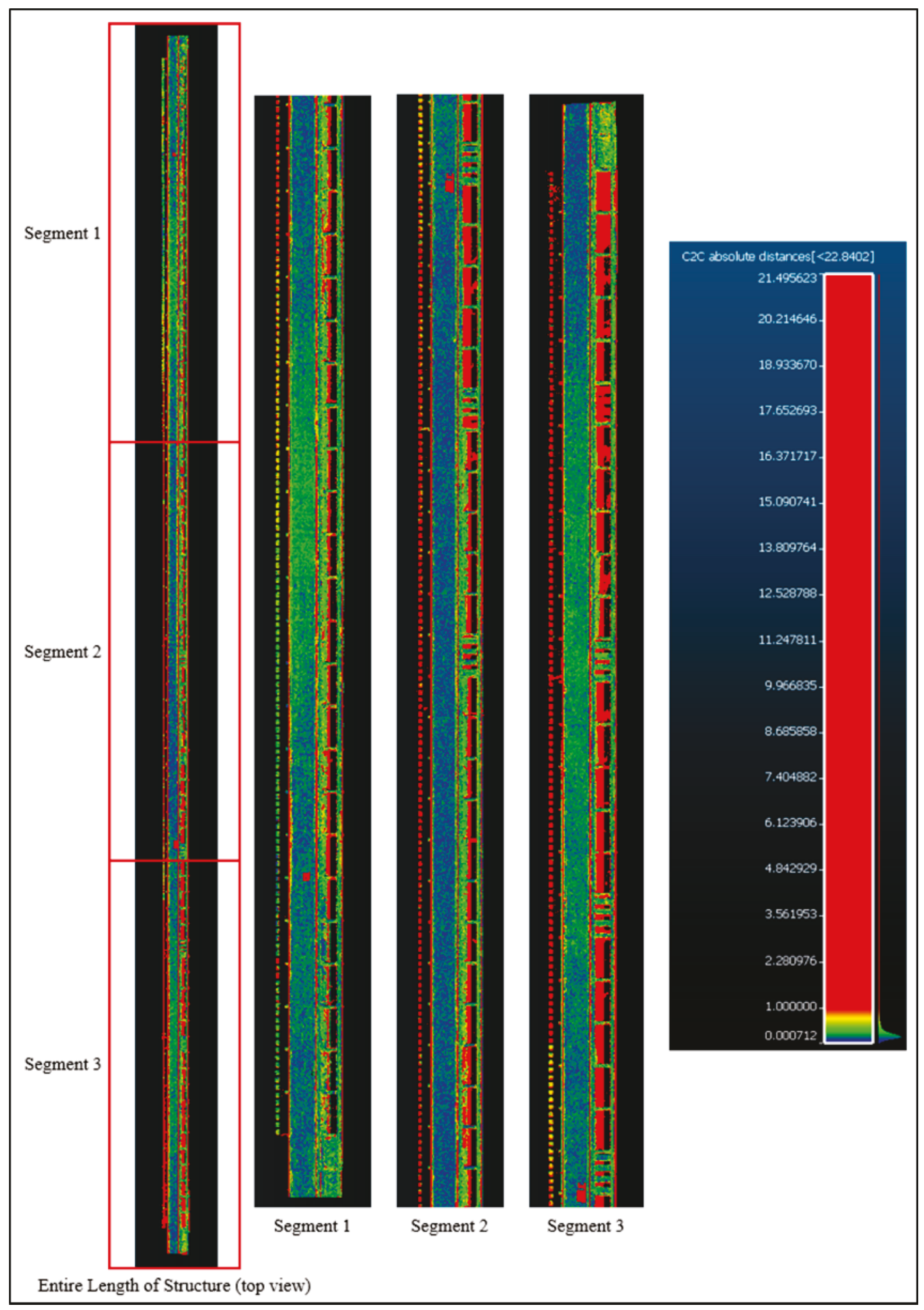


Figure 13. Result of the Cloud-to-Cloud Distance tool. The colors represent the nearest neighbor distance from the LiDAR point cloud to the SFM cloud. This figure displays a profile view.

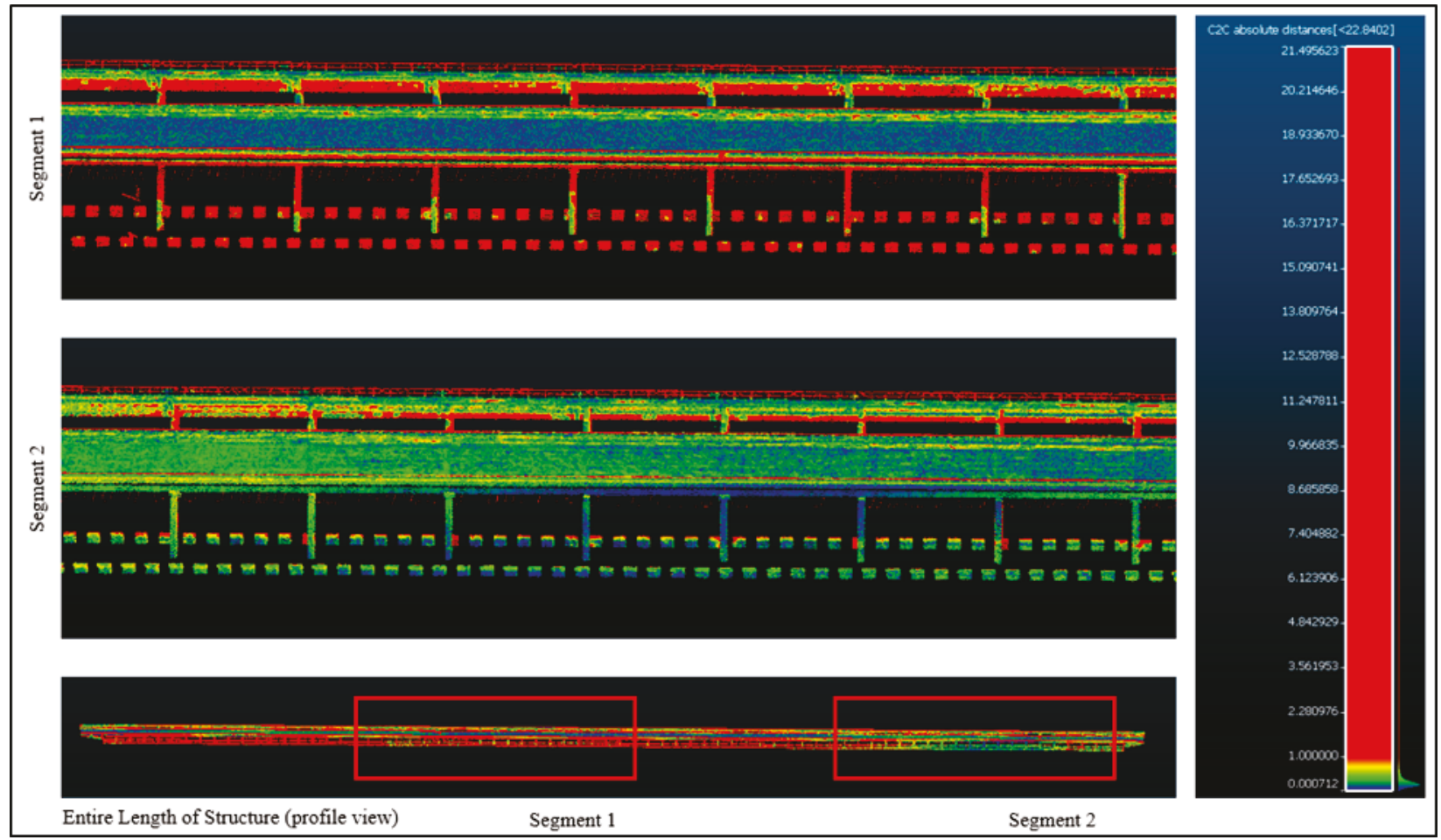

The shortest distance represented by the above figures is 0.000712 feet while the greatest is 21.50 feet. $94.82 \%$ of the measured cloud to cloud distances were between $0.0007 \mathrm{ft}$ and 2.7 feet while $0.0106 \%$ had a measured distance between 18.8 feet and 21.5 feet. The deck of the structure shows the tightest spatial agreement between the LiDAR and SfM point clouds with most distances falling below 0.5 feet. The areas of greatest distance were mostly caused by points existing in one point cloud and not existing in the other. In many areas the sides of the structure in the SfM point cloud were clipped out due to extreme clutter which caused these areas to have such a great distance between the two datasets. There were also segments of the structure along the sides where the two point cloud were slightly misaligned. This is reflected in the red and yellow colored regions in the point cloud colored by distance. It was also seen that the oblique images taken with the albris lead to areas of the point cloud that were slightly misplaced. This could have been caused by the oblique view of the ground control targets in the albris derived images. It is possible that this could have been corrected by placing ground control targets vertically on the side of the structure instead of laying them horizontally on the ground, allowing for more precise tagging of the control targets in the imagery. Figure 14 shows an oblique image taken by 
the albris, displaying a ground control target at the bottom of the field of view. Future oblique data collection should include ground control targets placed vertically on the structure. Not only would this allow for greater precision in ground control tagging, but it would also allow the sUAS pilot to fly closer to the structure which would increase resolution and overall accuracy of the point cloud.

Figure 14. An oblique image of the Overbank structure taken by the albris sUAS. The ground control target (circled in yellow) is displayed at the bottom of the image.

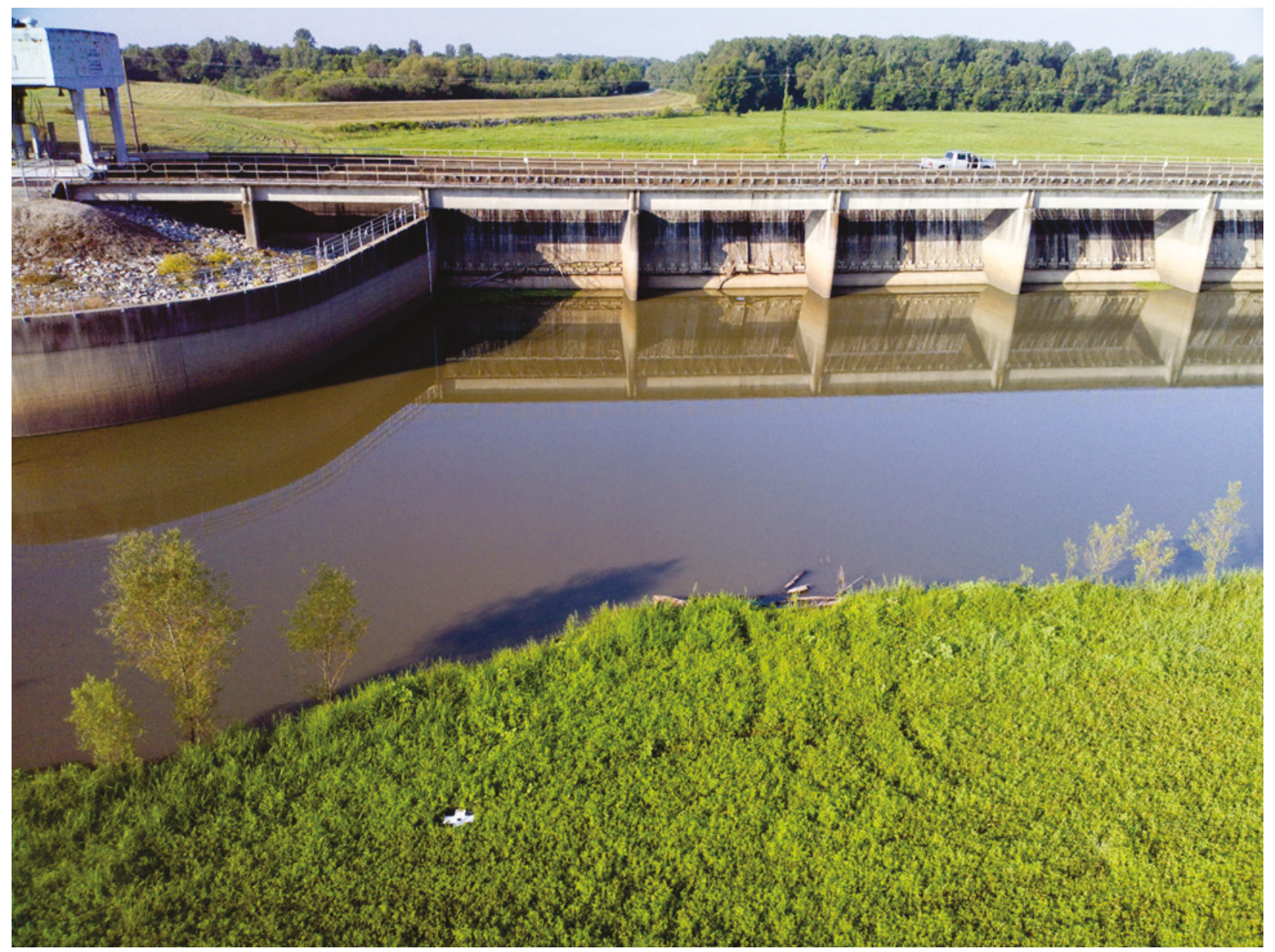

\subsection{Time and cost comparison}

A time and cost comparison was conducted between the two survey methods and is summarized in Figure 15. The approximate contracting cost reflects the approximate costs that a local surveying firm would charge for each service to survey the Overbank structure. The approximate equipment cost reflects the price of each platform. The time taken for survey and processing displays the time it took for each platform to survey the Overbank structure and the time it took to process each set of data. 
Figure 15. A time and cost comparison between the two survey methods.

\section{Approximate Contracting Cost}

- senseFly eBee survey - $\$ 3,550$ per day

- Pix4D processing - 6 hours at $\$ 89.70$ per hour $=\$ 538.20$

- Riegl RiCOPTER sUAS LiDAR survey $\$ 5,750$ per day

Approximate Equipment Purchase Cost

- $\quad$ senseFly eBee RTK - $\$ 29,564.70$

- senseFly albris - $\$ 30,434.25$

- Pix4D processing software - $\$ 8,700$

- Riegl RiCOPTER - $\$ 225,000$

Time Taken for Survey and Processing

- senseFly eBee RTK survey - 15 min

- senseFly albris survey $-30 \mathrm{~min}$

- Pix4D processing - $2 \mathrm{hrs} .35 \mathrm{~min}$

- CloudCompare processing $-6 \mathrm{hrs}$.

- Total - 9 hrs. $20 \mathrm{~min}$

- Riegl RiCOPTER Survey - 9 min

- LiDAR processing $-8 \mathrm{hrs}$.

- Total $-8 \mathrm{hrs} .9 \mathrm{~min}$ 


\section{Conclusion}

When visually comparing the two point clouds, the LiDAR collection appeared to be of higher quality due to the little amount of noise and clutter, the clean surfaces, and sharp edges. This point cloud would be easier to make precise measurements on, create a 3D mesh, or interpolate a digital surface model. The characteristics of the LiDAR point cloud showed that it was less dense and made up of fewer points. The accuracy analysis showed that it deviated slightly from the ground control network with an RMSE of 0.2761 feet. The cloud to cloud distance showed that it occupied the same approximate space as the SfM point cloud, especially along the deck of the structure. A sUAS LiDAR survey is slightly less time intensive but the cost is much higher than a SfM survey.

The initial SfM point cloud required extensive cleaning in order to have a model that was useful. Even after the spurious points were removed, some sections of the structure's side were not correctly reconstructed and were not of high enough quality to make precise measurements on. This however was not the case for the entire structure with the majority of the point cloud being of high quality. These areas of incorrectly reconstructed points were most likely caused by shadowing in the interior of each bay, and errors during the georectification. These setbacks could have been resolved by taking the images when the interior of the structure was most illuminated and shadowing was decreased, such as during an overcast day when the light is defused.

Future surveys will include vertical ground control targets on the side of the structure which will allow for more precise tagging of the targets during the photogrammetric processing and will allow the sUAS to fly closer to the structure, decreasing the amount of background features in the images and increasing the resolution. The SfM point cloud was denser and made up of more points than the LiDAR. The density is something that can be altered during the processing with Pix4D (https://pix4d.com/). For this study, the density was left at its default setting, but could be increased or decreased for future work. The extent of this point cloud occupied the same approximate extent as the LiDAR survey. The accuracy analysis showed it to have an RMSE of 0.0739 feet when determining how well it fit to the ground control target network. This low RMSE was to be expected since the model was constrained to these targets during the processing. 
The LiDAR was constrained to the same vertical control points, and was therefore expected to fit more precisely to the ground control targets. The cloud to cloud distance showed that there were large areas along the side of the structure that were either missing or misaligned relative to the LiDAR point cloud, and that the deck of the SfM point cloud and the LiDAR point cloud were aligned very well relative to one another. Deriving a quality point cloud of a structure by a SfM photogrammetric process is more time intensive but less expensive.

There are many variables that must be considered when determining the best data collection approach to use. Some of these variables include the following: the purpose of the survey, what the site looks like, whether or not there is water present, whether or not vertical objects will be surveyed, the time frame of the project, and the budget for the project. All of these dictate how data collection will be conducted. This study, as well as previous studies, have shown that SfM is typically less expensive than LiDAR and can be of high quality accuracy when the survey is executed properly. However, the SfM processing through photogrammetric software is typically computationally expensive and time extensive. Because SfM relies on passive sensors, it has no penetrating capabilities (like LiDAR) and therefore should not be used in heavily vegetated areas when the surface below the vegetation is the subject of interest. The nature of a passive sensor also leads to difficulties in generating data in areas of low light. Finally, SfM does not lead to quality data when the subject of interest lacks unique features for the processing algorithms to match on. This is one reason why it fails to reconstruct areas containing water. Other scenes that could pose difficulty during the SfM processing include snow, sand, large areas of concrete, tree canopies, and any other homogenous landscapes.

Aerial LiDAR surveying is typically more expensive than SfM photogrammetry, but often less time consuming in both the collection and processing. LiDAR is an active sensor and is capable of multiple returns. This makes it a better choice when attempting to survey areas that are obstructed by vegetation. An active sensor is not limited by the amount of light that falls upon the object or scene and therefore is more capable of surveying areas where low light or shadowing conditions occur. Currently, LiDAR sensors are fairly large, this is needed to deliver high enough quality to match the accuracy and density that can be seen through photogrammetric processes. A sensor of this quality, and this size, requires a large and complex sUAS in order to carry the heavy payload. As the 
miniaturization of sensors progresses, it could be expected to see a decrease in the cost associated with LiDAR systems and an increase of sUAS borne LiDAR surveys.

This work evaluated two different data collection approaches in order to obtain a 3D point cloud of a structure. LiDAR and SfM are different in many ways and these differences are reflected in the resultant point clouds. By analyzing the point clouds derived by each method, this study gained a greater understanding of how the data differs and how each method can be applied to solve real world questions. 


\section{References}

Girardeau-Montaut, Daniel. 2011. CloudCompare-Open Source project. OpenSource Project.

Lowe, D. G., 1999. Object recognition from local scale-invariant features. In Computer vision, 1999. The Proceedings of the Seventh IEEE International Conference on Computer Vision (2: 1150-1157).

U.S. Army Corps of Engineers, Vicksburg District. 2016. Standing Operating Procedure for Operation of SenseFly eBee RTK Unmanned Vehicle System, SOP Number 1.o. Vicksburg, MS: U.S. Army Corps of Engineers. Revision Number 1.o.

Wolf, P. R. and Dewitt, B. A., 2000. Elements of Photogrammetry: With Applications in GIS (Vol. 3). New York: McGraw-Hill. 


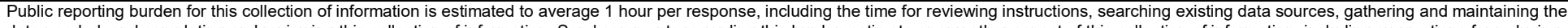

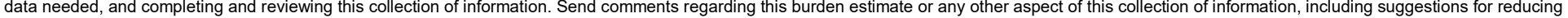

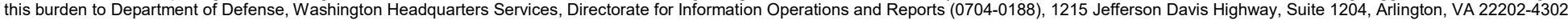

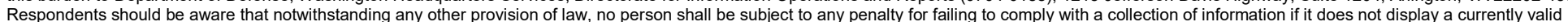
OMB control number. PLEASE DO NOT RETURN YOUR FORM TO THE ABOVE ADDRESS.

OMB control number. PLEASE DO NOT RETURN YOUR FORM TO THE ABOVE ADDRESS

\begin{tabular}{l|l} 
1. REPORT DATE (DD-MM-YYYY) & 2. REPORT TYPE
\end{tabular} August 2018

\section{TITLE AND SUBTITLE} Final

A Comparative Analysis of LiDAR and Structure from Motion Photogrammetry Utilizing a Small Unmanned Aerial System (sUAS) Approach for Structural Mapping and Inspection

\section{DATES COVERED (From - To)}

5a. CONTRACT NUMBER

\section{5b. GRANT NUMBER}

\section{5c. PROGRAM ELEMENT}

\section{AUTHOR(S)}

A Comparative Analysis of LiDAR and Structure from Motion Photogrammetry Utilizing small Unmanned Aerial System (sUAS) Approach for Structural Mapping and Inspection

\section{5d. PROJECT NUMBER}

5e. TASK NUMBER

\section{5f. WORK UNIT NUMBER}

$\mathrm{FC}_{5} \mathrm{H}_{3}$

\section{PERFORMING ORGANIZATION NAME(S) AND ADDRESS(ES)}

U.S. Army Engineer Research and Development Center (ERDC)

Information Technology Laboratory (ITL)

Waterways Experiment Station, 3909 Halls Ferry Road

8. PERFORMING ORGANIZATION REPORT NUMBER

Vicksburg, MS 39180-6199

ERDC/ITL TR-18-1

\section{SPONSORING / MONITORING AGENCY NAME(S) AND ADDRESS(ES)}

U.S. Army Engineer Research and Development Center (ERDC)

Waterways Experiment Station, 3909 Halls Ferry Road

Vicksburg, MS 39180-6199

10. SPONSOR/MONITOR'S ACRONYM(S) ERDC

11. SPONSOR/MONITOR'S REPORT NUMBER(S)

\section{DISTRIBUTION / AVAILABILITY STATEMENT}

Approved for public release; distribution is unlimited.

\section{SUPPLEMENTARY NOTES}

\section{ABSTRACT}

The U.S Army Corps of Engineers (USACE) Field Operating Activities invest significant amounts of project time and funding on survey data collection by conventional methods. This data collection supports a variety of Civil Works projects spanning wide-ranging geographies and site conditions to include hard to access terrain. Innovations in small Unmanned Aerial Systems (sUAS, e.g., drones) and data processing techniques purport to produce survey grade data more efficiently and with greater coverage than conventional survey collection in hard to access terrain conditions.

USACE involvement in construction of our Nation's aging infrastructure will require extensive surveying. These efforts will support design and site assessments, cultural resources, and environmental determinations typically required by the National Environmental Policy Act, Endangered Species Act, Clean Water Act, National Historic Preservation Act, Migratory Bird Treaty Act, Clean Air Act, and the Archaeological Resources Protection Act.

Efforts using sUAS provide an efficient and effective technology to support these initiatives. However, sUAS technology also offers many diverse platforms and collection sensors that provide varying types of results. An evaluation of sensor types and sUAS platforms is provided.

\section{SUBJECT TERMS}

Surveying, Engineering inspection, Optical radar, Photogrammetry, Data collection platforms, Drone aircraft, Micro air vehicles

\section{SECURITY CLASSIFICATION OF:}

\section{a. REPORT}

Unclassified

\section{b. ABSTRACT}

Unclassified

\section{c. THIS PAGE}

Unclassified

\section{LIMITATION} OF ABSTRACT

SAR
18. NUMBER OF PAGES

37 19a. NAME OF RESPONSIBLE PERSON

19b. TELEPHONE NUMBER (include area code) 